\title{
Medication Compliance amongst Diabetic Patients in Ilorin, Nigeria
}

\author{
Fatima Iyabo Abdulazeez ${ }^{1}$, Moses Omole ${ }^{2}$, Sheriff Lekan Ojulari ${ }^{3}$

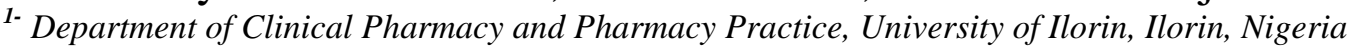 \\ 2- Department of Clinical Pharmacy and Pharmacy Administration, University of Ibadan, Ibadan, Nigeria \\ ${ }^{3-}$ Department of Physiology, University of Ilorin, Ilorin, Nigeria
}

\begin{abstract}
:
Purpose: Diabetes is a serious condition on the global scale. There is a rapidly increasing prevalence and as such, patients' compliance with diabetic medication is a great cause for concern ${ }^{2}$. This study was carried out to investigate the degree of patients' compliance with their prescribed medications, factors responsible for noncompliance and how compliance can be enhanced.

Methods: The study involved 220 diabetic patients on anti-diabetic medication (insulin, metformin and gliclazide) visiting the out-patient clinic of the University of Ilorin Teaching Hospital, Nigeria, who met specific criteria. Questionnaires and patient interviews were used to gather information.

Results: From our results, 162 patients (73.64\%) were non-compliant with the remaining 58 patients (26.36\%) being compliant with medications. 22 of the compliant patients were males while 36 were females. 23 of the compliant patients had no educational qualification while 35 had either primary, secondary and tertiary education. Results showed significant association $(P<0.05)$ between patients financial status and compliance. However, there was no significant association $(P>0.05)$ between number of prescribed medications, side effects, patients' level of education, patients' belief of efficacy of medication and compliance.

Conclusion: Non-compliance among diabetics on medication was established and it was recommended that compliance be improved through various strategies that include improved patients' education.
\end{abstract}

Keywords: compliance, diabetics, medication, prescribed

\section{Introduction}

For some decades now, patients' non-compliance with therapeutic regimen has been recognized as a challenge to the successful delivery of healthcare. Drug treatment relies heavily on the cooperation of the patient for self administration, as patients' compliance in ambulatory care is an important link between medical process and treatment outcome ${ }^{[1]}$.

Diabetes is a serious condition for the individual and on the global scale. There is a rapidly increasing prevalence and as such, patients' compliance with diabetic with diabetic medication is a great cause for concern ${ }_{[2]}$.

The prevalence of diabetes for all age groups worldwide was estimated to be $2.8 \%$ in 2000 and $4.4 \%$ in $2030{ }^{[3]}$. The total number of people with diabetes is projected to rise from 171 million in 2000 to 366 million in $2030^{[3]}$. The prevalence is higher in men than women ${ }^{[3]}$.

Helping patients adhere to often complex treatment regimens and achieve tight blood glucose control is a challenge that must be addressed during all phases of diabetic treatment ${ }^{[4,5]}$.

The vast majority of diabetic outpatients self administer their own medications. Thus patients' attitude and beliefs can strongly influence the effectiveness of interventions. Patients' perceptions of the importance of glycemic control and their self-care ability have been identified too as factors that may affect patients' compliance ${ }^{[6,7]}$.

This study therefore, aims to demonstrate lack of compliance with prescribed medications in diabetics, identify factors affecting compliance and seek ways of enhancing patients' compliance.

\section{Methods}

The research methods used to gather information for this study was mainly questionnaires and patient interviews. Study population includes diabetic patients that visited the outpatient clinic of the endocrine unit of the University of Ilorin Teaching Hospital over a period of 16 weeks.

\section{Inclusion criteria:}

The criteria for inclusion in the study include

1- The patient must have been properly diagnosed as diabetic, that is having a grossly elevated random blood glucose above a specified range (whole blood glucose $>6.7 \mathrm{mmol} / \mathrm{L}$ or plasma glucose $7.8 \mathrm{mmol} / \mathrm{L}$ ) for a 
long period of time; or after a formal 75g OGTT has been performed, having a venous plasma glucose level $2 \mathrm{hrs}$ after loading as $>11.1 \mathrm{mmol} / \mathrm{L}$.

2- Patients must have been on drug treatment for upwards of 6 months. Patients who were newly diagnosed were excluded from this study.

3- Patients on dietary modifications and/ or exercise alone were not included

\section{Sample size and sampling technique:}

300 patients that visited the clinic over a period of about 16 weeks were used in this study. 80 of the patients did not meet the inclusion criteria; a total of 220 diabetic patients were therefore used in the study. They were selected using random sampling technique and only those who met the inclusion criteria were used. Study design was descriptive.

\section{Procedure:}

On each clinic day, patients were randomly selected form the total population of patients that visited. The study and its importance were explained to them and their consent to participate in the study was sought and obtained. The questionnaires were administered to some of them and to a larger number; the questions were read out to them and filled. The patients were also interviewed so as to recognize some evidences that were subjective that point to non-compliance but which may be difficult to reflect in the questionnaires.

\section{Statistical analysis:}

All results were expressed as mean \pm SEM. Data was analyzed by one-way analysis of variance (ANOVA) and Duncan New Multiple Range Test (DMRT). Differences in means were considered significant at $\mathrm{P}<0.05$. All analysis was performed using SPSS 17.

III. Results

Table 1: Sex distribution

\begin{tabular}{|l|l|l|l|}
\hline Gender & $\begin{array}{l}\text { No. of Compliant patients } \\
(\%)\end{array}$ & $\begin{array}{l}\text { No of Non-compliant patients } \\
(\%)\end{array}$ & Total (\%) \\
\hline Male & $22(37.69)$ & $78(48.15)$ & $100(45.54)$ \\
\hline Female & $36(62.07)$ & $84(51.85)$ & $120(54.55)$ \\
\hline Total & $58(26.39)$ & $162(73.63)$ & $220(100)$ \\
\hline
\end{tabular}

Table 2: Age distribution/Group

\begin{tabular}{|l|l|l|l|}
\hline Age & Number of compliant patients (\%) & $\begin{array}{l}\text { Number of non- compliant } \\
\text { Patients (\%) }\end{array}$ & Total (\%) \\
\hline$<40$ & $12(5.46)$ & $5(2.27)$ & $17(7.73)$ \\
\hline $40-49$ & $8(3.64)$ & $38(17.27)$ & $46(20.91)$ \\
\hline $50-59$ & $14(6.36)$ & $38(17.27)$ & $52(23.64)$ \\
\hline $60-69$ & $18(8.18)$ & $64(29.09)$ & $82(37.30)$ \\
\hline$>70$ & $6(2.72)$ & $16(7.27)$ & $22(10.00)$ \\
\hline Total & $58(26.36)$ & $162(73.64)$ & $220(100.00)$ \\
\hline
\end{tabular}

Table 3: Educational qualification of diabetic patients:

\begin{tabular}{|l|l|l|l|l|l|l|}
\hline $\begin{array}{l}\text { Education } \\
\text { Qualification } \\
(\%)\end{array}$ & $\begin{array}{l}\text { Compliant } \\
\text { Males } \\
\text { Patients }(\%)\end{array}$ & $\begin{array}{l}\text { Compliant } \\
\text { Females } \\
\text { Patients }(\%)\end{array}$ & $\begin{array}{l}\text { Total No. of } \\
\text { Compliant } \\
\text { Patients }(\%)\end{array}$ & $\begin{array}{l}\text { Non-compliant } \\
\text { Male patients } \\
(\%)\end{array}$ & $\begin{array}{l}\text { Non-compliant } \\
\text { Female } \\
\text { Patients }(\%)\end{array}$ & $\begin{array}{l}\text { Total No. } \\
\text { Non-compliant } \\
\text { Patients }(\%)\end{array}$ \\
\hline None (34) & $10(4.55)$ & $13(5.91)$ & $23(10.45)$ & $25(11.36)$ & $27(12.27)$ & $52(23.64)$ \\
\hline Primary (18) & $2(0.91)$ & $5(2.27)$ & $7(3.18)$ & $16(7.27)$ & $17(7.72)$ & $33(15.00)$ \\
\hline Secondary & $5(2.27)$ & $12(5.45)$ & $17(7.72)$ & $21(9.55)$ & $21(9.55)$ & $42(19.09)$ \\
\hline Tertiary (21) & $5(2.27)$ & $6(2.73)$ & $11(5.00)$ & $16(7.27)$ & $19(8.64)$ & $35(15.91)$ \\
\hline Total $(100)$ & $22(10)$ & $36(16.36)$ & $58(26.36)$ & $78(35.45)$ & $84(38.18)$ & $162(73.64)$ \\
\hline
\end{tabular}

Table 4: Financial status of diabetic patients

\begin{tabular}{|l|l|l|l|l|l|l|}
\hline $\begin{array}{l}\text { Financial } \\
\text { Status }\end{array}$ & $\begin{array}{l}\text { Compliant } \\
\text { Males } \\
\text { Patients }(\%)\end{array}$ & $\begin{array}{l}\text { Compliant } \\
\text { Females } \\
\text { Patients }(\%)\end{array}$ & $\begin{array}{l}\text { Total No. of } \\
\text { Compliant } \\
\text { Patients (\%) }\end{array}$ & $\begin{array}{l}\text { Non-compliant } \\
\text { Male patients } \\
(\%)\end{array}$ & $\begin{array}{l}\text { Non-compliant } \\
\text { Female } \\
\text { Patients }(\%)\end{array}$ & $\begin{array}{l}\text { Total No. } \\
\text { Non-compliant } \\
\text { Patients }(\%)\end{array}$ \\
\hline High & $3(1.36)$ & $6(2.73)$ & $9(4.09)$ & $5(2.27)$ & $4(1.82)$ & $9(4.09)$ \\
\hline Medium & $12(5.45)$ & $26(11.82)$ & $38(17.27)$ & $46(20.91)$ & $43(19.55)$ & $89(40.45)$ \\
\hline Low & $7(3.18)$ & $4(1.82)$ & $11(5.00)$ & $27(12.27)$ & $37(16.81)$ & $64(29.09)$ \\
\hline Total & $22(10)$ & $36(16.36)$ & $58(26.36)$ & $78(35.45)$ & $84(38.18)$ & $162(73.64)$ \\
\hline
\end{tabular}


Table 5: Belief in medication efficacy among diabetic patients

\begin{tabular}{|l|l|l|l|l|l|l|}
$\begin{array}{l}\text { Belief } \\
\text { medication } \\
\text { Efficacy }\end{array}$ & $\begin{array}{l}\text { Compliant } \\
\text { Males }\end{array}$ & $\begin{array}{l}\text { Compliant } \\
\text { Females } \\
\text { Patients }(\%)\end{array}$ & $\begin{array}{l}\text { Total No. of } \\
\text { Compliant } \\
\text { Patients (\%) }\end{array}$ & $\begin{array}{l}\text { Non-compliant } \\
\text { Male patients } \\
(\%)\end{array}$ & $\begin{array}{l}\text { Non-compliant } \\
\text { Female } \\
\text { Patients }(\%)\end{array}$ & $\begin{array}{l}\text { Total No. } \\
\text { Non-compliant } \\
\text { Patients }(\%)\end{array}$ \\
\hline Effective & $16(7.27)$ & $18(8.18)$ & $34(15.46)$ & $37(16.82)$ & $56(25.46)$ & $93(42.27)$ \\
\hline Non-effective & $6(2.73)$ & $18(8.18)$ & $24(10.91)$ & $41(18.63)$ & $28(12.72)$ & $69(31.36)$ \\
\hline Total $(100 \%)$ & $22(10)$ & $36(16.36)$ & $58(26.36)$ & $78(35.45)$ & $84(38.18)$ & $162(73.64)$ \\
\hline
\end{tabular}

\section{Discussion}

We assessed compliance with drug medication among diabetics visiting the outpatient clinic of the endocrine unit of the University of Ilorin Teaching Hospital over a period of 16 weeks. We established noncompliance, identified factors that could lead to non-compliance and suggested possible ways to reducing this problem.

Diabetes is a serious condition for the individual and on the global scale. There is a rapidly increasing prevalence and as such, patients' compliance with diabetic with diabetic medication is a great cause for concern [2].

Our study showed that 58 patients (26.36\%) were compliant with their medication regimens, while 162 patients (73.64\%) were non- compliant. The above statement supports the assertion of Urquhart J. (1994) that about one-third or more of patients have poor compliance with prescribed medications irrespective of disease ${ }^{[8]}$.

About $62 \%$ of patients on anti-diabetic therapy discontinue treatment within one year while some use their medications irregularly ${ }^{[5]}$. Electronic monitoring methods that have been used to measure compliance also reveal that greater than $30 \%$ of patients omit many prescribed doses, irrespective of disease, symptoms or prognosis ${ }^{[8]}$.

Forgetfulness was found to be the most common reason for non-compliance among the diabetic patients used in the study. From the result, about 95 patients (43.18\%) admitted to skipping doses of their medications at one time or the other. This included patients on glibenclamide and metformin alone and also those patients on insulin. If patients have a hectic lifestyle or irregular schedule, these also raise a risk of patients forgetting to take their medications ${ }^{[9]}$

The results of our study showed that there is a significant association $(\mathrm{P}<0.05)$ between patients' financial status and compliance with prescribed medications. The cost to drugs serves as obstacle to compliance with most patients irrespective of diseases. A patient experiencing financial constraint may find it difficult to spend money on drug particularly if immediate change in health conditions does not show ${ }^{[10]}$. Butler et al (1996) found that lack of compliance may be related to perceived financial distress by the patient rather than an actual cost of the medications or the source of payment.

The side effects of drugs seem to be another reason though there was no significant relationship $(\mathrm{P}>0.05)$ between side effects and compliance. The fears of hypoglycemia and weight gain are other factors that can adversely influence patients' ability to adhere to treatment ${ }^{[7]}$. Whereas hypoglycemia is less common among patients with Type 2 diabetes mellitus compared to those with Type 1, its fear may inhibit both physicians and patients from optimizing care ${ }^{[11]}$. From the study, it was gathered that diabetic patients on insulin, whether prescribed alone or in combination with glibenclamide or metformin or both had their compliance affected because of constant injection of insulin which they claimed can be quite tasking day in day out. The patients gave some side effects which included nausea, gastrointestinal disturbances, mild headache, etc as some reasons that might have affected their compliance with their medication. Adherence to medications appears to decrease with perceived and real side effects and patients need to be counseled to maintain compliance.

There was no significant association $(\mathrm{P}>0.05)$ between patients' belief of efficacy of prescribed medication and compliance. The vast majority of diabetic patients self-administer their own medications, as such patients' attitude and beliefs can strongly influence their compliance; though from this study it seems most patients still comply poorly even with the belief that the medications are efficient. This finding is supported by J Urquhart, whose findings show that provision of information on the drugs and their efficacy does little to ensure that doses are taken regularly and on time ${ }^{[8]}$

Attitudinal barriers to non-compliance represent intrinsic beliefs held by the patients that have been shaped by psychological and social factors unique to these individual. Attitude interacting with social, psychology, economic and structural factors influence patients' behavior and determine compliance ${ }^{[10]}$

No significant association was seen between the number of prescribed medication and patients' compliance. This does not however conform to most other studies as adherence to medication regimen appears to decrease with an increasing number of drugs and number of doses per day ${ }^{[10]}$. In this study, those patients placed on a combination of two of the anti-diabetic drugs (insulin, glibenclamide and metformin) formed the largest number of non-compliant patients. With every additional medication, a patient must take each with its own dosing instructions thus the potential for error becomes greater. Likewise, the more complex the regimen, 
the worse the compliance will be. Thus if all medicines are to be taken at the same time of day, compliance will be higher than of several different time throughout the day are used ${ }^{[10,12]}$

Though one would expect that the number of patients placed on three (3) drugs (insulin, glibenclamide, and metformin), would have the highest number of non-compliant patients as compared to patients on one or two anti-diabetic medication. The number of prescribed medications however may not always result in poor compliance as a patient on two or more drugs has to take them once a day at the same time may be more compliant than a patient on one drug who has to take it three times daily.

\section{Conclusion:}

Our study also showed that there was no significant association $(\mathrm{P}>0.05)$ between the level of educational qualification and compliance with prescribed medication. Though it can be reasoned that the more educated a patient, the better he will be able to understand his disease state and comprehend the instructions given on his drug as which may enhance his compliance. However, this is not always so, as pharmacists, physicians and nurses who are well educated and have good knowledge about diseases and drugs are not always good compliers. This assertion supports the result of this study.

It is thus becoming clear that medication adherence is a complex behavior and development of effective intervention can improve compliance only when mechanisms underlying the behaviors are better understood. It is recommended that patients should be educated on the importance of complying with prescribed drug regimen, physicians should prescribe the drug regimen least likely to result in adverse effects and monitoring for achievement of normal blood glucose level should be carried out as often as needed.

Limitations of Study: A major limitation of our study was the tool used in collection of the data (Questionnaire). This method relied on asking patients about their compliance and no observation whatsoever was involved. There was also the tendency for patients to exaggerate their compliance and also for some patients to deliberately indicate a poor level of compliance.

\section{Reference}

[1] Eraker SA, Kirsht JP, Becker MH. Understanding and improving patients' compliance. Ann Med 1984; 100: 258-268.

[2] International Diabetes Federation (IDF). Diabetes Atlas $2^{\text {nd }}$ Edition.

[3] Sarah W, Gojka R, Anders G, Richard S, Hilary K. Global prevalence of diabetes (estimates for the year 2000 and projections for 2030). Diabetes Care Journal 2004; 27: 1047-1053

[4] Lutfey KE, Wishner W. Beyond “compliance is "adherence” Improving the prospect of diabetes care. Diabetes care 1999; 22: 63539.

[5] Jayan D, Lawrence B, and Richard GJ. Feature article on factors influencing parents acceptability of diabetic treatment regimen $2000 ; 1-9$

[6] Blaum CS, Velez L, Hiss RG, Halter JB. Characteristics related to poor glycaemic control in NIDDM patients in community practice. Diabetes care 1997; 20: 7-11

[7] Thompson CJ, Cunnings JF, Chalmers J, Gould C, Newton RW. How have patients reacted to the implications of the DCCT? Diabetes care 1996; 19: 876-79

[8] Urquhart J. Patient non compliance with drugs regimens. Measurement, clinical correlates. Economic Impact in European Heart Journal 1996; 17: 8-15

[9] Index of Essential medicines 2002-2003, 149-176

[10] Counseling to enhance compliance, Pharmacist-patient-consultation programme, PPCP-unit 3

[11] Korzon-Burakowska A, Hopkins D, Matyka K, Lomas J, Pernet A, Macdonald I, Amiel S. Effects of glycaemic control on protective response against hypoglycemia in Type 2 diabetes, Diabetic care 1998; 21: 283-90

[12] Winfield J.; Richards R. Compliance in Pharmaceutical practice. Churchill Livingstone; 1999.444 p. 